\title{
Expression of the Low Molecular Weight Cyclin E is Early Event in Colorectal Carcinogenesis
}

\author{
Young Hak Jung, M.D. ${ }^{1}$, Seong-Hoo Choi $^{2}$, and Dong-Guk Park, M.D., Ph.D. ${ }^{1,3}$
}

Departments of ${ }^{1}$ Surgery, ${ }^{2}$ Biochemistry and ${ }^{3}$ Institute of Life Science, School of Medicine, Dankook University, Cheonan, Korea

Purpose: Cyclin $E$ is essential for the transition from the $\mathbf{G} 1$ to $S$-phase of the cell cycle, and plays important roles in carcinogenesis in many cancers. Especially, low molecular weight cyclin $E$ is overexpressed in breast cancer and its level of expression correlates well with the progression and prognosis. Although the cyclin $E$ level is amplified, and overexpressed, in many cancers, including colorectal cancer, the role of low molecular weight cyclin $E$ in colorectal cancer remains to be studied. Therefore, the expression of low molecular weight cyclin $E$ in various stages of colorectal tumors was studied.

Materials and Methods: The expression of low molecular weight cyclin $E$ was analyzed in 45 tumors, and compared with paired normal mucosa from the same patients ( 6 adenomas, 11 stage A, 14 stage $B$ and 14 stage

\section{INTRODUCTION}

Eukaryotic cells are driven through the cell cycle by successive activation and inactivation of cyclin-dependent kinases (CDKs). The activities of these CDKs are regulated positively by binding with their regulatory subunit, the cyclins, and negatively by binding of CDK inhibitors (CKIs) (1). The G1 cyclins, cyclin D and cyclin E, are essential for the progression from the $\mathrm{R}$ point to $\mathrm{S}$ phase (2). Cyclin $\mathrm{E}$ appears during the G1 phase of the cell cycle, increases sharply in the late G1 phase, which is followed by degradation by the ubiquitinproteosome pathway (3).

Cyclin E can bind to Cdk2, with a peak of associated activity at the G1/S boundary, and the complex formed has been shown to play an essential and rate-limiting role in the G1/S transition and initiation of DNA replication (4). The cyclin E/Cdk2 complex phosphorylates the retinoblastoma protein $(\mathrm{pRb})$ and main-

Correspondence: Dong-Guk Park, Department of Surgery, School of Medicine, Dankook University, Anseo-dong San-29, Cheonan, Chungnam 330-714, Korea. (Tel) 82-41-550-3931, (Fax) 8241-550-3905, (E-mail) dkpark@dankook.ac.kr

Received June 30, 2003, Accepted August 27, 2003

This study was funded by Life Science Research Center of Dankook University Medical Center in 2001.
C colorectal cancers) by Western blot analysis. The expres sion of low molecular weight cyclin $E$ was also analyzed in normal colon mucosa from 12 healthy normal controls.

Results: The low molecular weight cyclin E was expressed exclusively in all stages of colon tumors, but not in the normal mucosa from the same patients or in the normal controls. However, there was no correlation between tumor progression and the degree of expression of low molecular weight cyclin $E$.

Conclusion: The expression of low molecular weight cyclin $E$ is suggested to be an early event in colorectal carcinogenesis. (Cancer Research and Treatment 2003; $35: 419-424$ )

Key Words: Cyclin E, Colorectal neoplasm, Cell cycle

tains it in a hyper-phosphorylated state $(5,6)$. However, unlike the D-type cyclins, cyclin $\mathrm{E}$ is essential for the cell cycle progression in pRb-deficient cells, with the ectopic expression of cyclin E bypassing pRb-mediated cell cycle arrest. It has been suggested there is a fundamental difference between the cyclin $\mathrm{D}$ and cyclin $\mathrm{E}$ complexes, and that other key rate-limiting substrates also exist for cyclin E/Cdk2. Cyclin E can replace all functions of cyclin D1 (7). In addition to its important role of cell cycle progression, cyclin $\mathrm{E}$ also plays a role in cellular senescence (8), development (9) and in the control of the signal transduction through $\mathrm{pRb}$ and E2F $(7,8)$. Some other studies have reported that the cyclin $\mathrm{E}$ is upregulated during cellular differentiation and aging (10).

Cyclin E gene is amplified, and over-expressed, in many cancers, including breast, colon, gastric, lung and kidney (11 14). In breast cancer especially, the elevated expression of cyclin $\mathrm{E}$ protein level is known as an independent prognostic factor, and is associated with decreased p $27^{\mathrm{Kip} 1}$ levels and lymphatic metastasis (11). The low molecular weight (LMW) cyclin $\mathrm{E}$ protein is especially expressed exclusively in breast cancer tissues, with breast cancer cell lines and this LMW cyclin $\mathrm{E}$ acting as a prognostic factor. The LMW cyclin E expression is also related with tumor progression, but the exact mechanism as to why the LMW cyclin E is expressed only in cancer tissues and cancer cell lines remains unclear. It has been suggested that the LMW cyclin E was generated by a posttranslational modification due to protease $(15,16)$. 
The development of colorectal cancer depends on two distinct molecular mechanisms, microsatellite and chromosomal instabilities, and both are characterized by genetic instability. Recently, the relationship between the overexpression of the cyclin E, and the chromosomal and microsatellite instabilities $(17,18)$ was reported. Some reports have suggested that the LMW form of cyclin E to be detected in colon cancer (19), but its role in colorectal cancer remains to be studied.

Therefore, it is our hypothesis that this low molecular weight cyclin $\mathrm{E}$ protein might have important effects in colorectal carcinogenesis. In this study, the expression of the LMW cyclin E protein was studied in normal colon mucosa, adenoma and colorectal cancer tissues, and compared with the surrounding normal tissues. It was shown that the LMW cyclin E protein was expressed exclusively in the colon tumor tissue, and appeared from small colon adenomas in the early stage of colon carcinogenesis. To our knowledge, this is the first report that LMW cyclin E has a role in the early stage of colon cancer carcinogenesis.

\section{MATERIALS AND METHODS}

\section{1) Colorectal cancer tissues}

Twelve normal colon mucosa tissues were obtained from volunteers during colonoscopies. Six colon tubular adenoma (verified histologically, less than $1.0 \mathrm{~cm}$ ) tissues were obtained, with consent, during the colonoscopies, along with 39 colorectal cancer tissues, with paired surrounding normal mucosa. According to the modified Astler-Coller staging system, 11 stage A, 14 stage B and 14 stage $\mathrm{C}$ cancer tissues were used for this experiment. The paired normal mucosa was obtained from the sites most proximal from the tumors. These tissues were quickly frozen in the aqueous nitrogen, and stored at $-80^{\circ} \mathrm{C}$ until required.

\section{2) Preparation of tissue homogenate}

The colorectal cancer and surrounding normal tissues were homogenized in ice-cold tissue homogenate buffer, containing $25 \mathrm{mM}$ Tris- $\mathrm{HCl}$ ( $\mathrm{pH}$ 7.4), $1 \mathrm{mM}$ EDTA, $1 \mathrm{mM}$ PMSF, 1 $\mathrm{mg} / \mathrm{ml}$ each of leupeptin, antipain, and aprotinin, $0.1 \% \mathrm{NP}-40$, $250 \mathrm{mM} \mathrm{NaCl}, 5 \mathrm{mM}$ DTT and $10 \mathrm{mM} \mathrm{NaF}$. The homogenate was centrifuged at $14,000 \mathrm{rpm}$ for $15 \mathrm{~min}$ at $4^{\circ} \mathrm{C}$, and the supernatant stored at $-80^{\circ} \mathrm{C}$ until required. The protein concentration was determined by the Bradford microassay (BioRad, Hercules, CA), with equal amounts of total protein used for

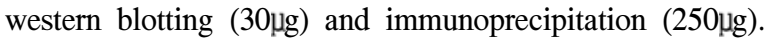

\section{3) SDS-PAGE and Western blotting}

Thirtyug of each supernatant were resolved by $12 \%$ sodium dodecyl polyacrylamide gel electrophoresis (SDS-PAGE), according to the method of Laemmli (20). The samples analyzed by SDS-PAGE were transferred to a nitrocellulose membrane (BioRad) using a semidry transfer system (BioRad), and the blots probed with anti-cyclin E specific (monoclonal, HE12, Santa Cruz Biotech, Santa Cruz, CA, $1: 1,000$ dilution) and anti-cdk2 specific antibodies (monoclonal, M2, Santa Cruz, 1 : 1,000 dilution), overnight at $4^{\circ} \mathrm{C}$. As a secondary antibody, peroxidase-conjugated IgG (goat anti-mouse IgG; Santa Cruz, $1: 2,500$ dilution) was used, followed by enhanced chemilu- minescence (ECL, Amersham Life Science, Inc.) detection, following the manufacturer's protocol. The amount of protein was controlled by the Erk protein expression. The experiments were performed at least three times. The densities of the immunoblotted bands were measured using a Luminescent Image Analyzer LAS-3000 (Fuji Film, Japan), employing Multi Gause V2.02 software. The protein expression was interpreted as increased when the density of the immunoblotted band showed a two-fold increase over that of the normal mucosa.

\section{4) Immunoprecipitation}

Two and hundreds fifty $\mu \mathrm{g}$ of the supernatant was precleared overnight with $20 \mu \mathrm{l}$ of a pre-equilibrated $50 \%(\mathrm{v} / \mathrm{v})$ protein A/G-agarose bead slurry (Santa Cruz). Then, 20ul of anticyclin $\mathrm{E}$ or anti-cdk2 antibodies was incubated overnight with $20 \mathrm{ul}$ of the protein A/G-agarose beads. After centrifugation for $5 \mathrm{~min}$ at $6,000 \mathrm{rpm}$, the beads fixed with antibody were placed in the precleared supernatant and incubated for 2 hours. The agarose beads were sedimented by centrifugation, and washed three times with Tris buffered saline $(10 \mathrm{mM}$ Tris- $\mathrm{HCl}$ and 150 $\mathrm{mM} \mathrm{NaCl}$ at $\mathrm{pH} 8.0$ ) containing $0.1 \%$ of Tween-20. All the above-mentioned incubations were carried out at $4^{\circ} \mathrm{C}$, with constant agitation using a head-over-tail-rotator. After the addition of SDS sample buffer and boiling for $5 \mathrm{~min}$, the immunoprecipitated beads were resolved by $12 \%$ SDS-PAGE, transferred to a nitrocellulose membrane, and the cyclin E or cdk2 proteins detected as described above.

All other unspecified chemicals were purchased from Sigma Biochemistry Co. (St. Louis, MO).

\section{5) Statistical analysis}

The significance of the differences among the densities was determined by Student's t-tests between the tumor and paired normal mucosa, and by the Fischer's exact method between the tumor progressions and the degree of expression. A $p$ value of less than 0.05 was considered statistically significant.

\section{RESULTS}

\section{1) LMW cyclin $\mathbf{E}$ expression in normal colonic mucosa and adenoma}

The normal colon mucosa was taken, with consent, from 12 healthy people during a colonoscopy. They had had no abnormal pathology in the entire colon, history of colon polyps or any abdominal operation. All the colon adenomas were diagnosed as tubular adenomas, with a size less than $1 \mathrm{~cm}$, and showed no dysplasia or carcinomatous components. In the normal mucosa, variable levels of cyclin E protein expression were noted, but the LMW cyclin E protein was not expressed in the Western blot analysis. All the cases showed three different sized cyclin $\mathrm{E}$ proteins-one major cyclin $\mathrm{E}$ band $(51 \mathrm{kDa})$ and two minor faint bands (45 and $43 \mathrm{kDa}$ ); suggestive of cyclin E protein products from alternative splicing (Fig. 1A, upper panel). However, in most of the adenomas (5 adenomas out of $6,83 \%)$ the total cyclin $\mathrm{E}$ protein expression was increased relative to the surrounding normal mucosa, and an increased LMW cyclin E expression was especially marked in the adenoma compared to the surrounding normal colon mucosa. The surrounding normal tissues showed the same cyclin E pro- 
Table 1. Expression of LMW cyclin E in normal colon mucosa and various stages of colorectal cancer with paired surrounding normal mucosa

\begin{tabular}{|c|c|c|c|c|c|c|}
\hline & $\begin{array}{c}\text { Normal } \\
\text { colon mucosa } \\
(n=12)\end{array}$ & $\begin{array}{c}\text { Adenoma } \\
(n=6)\end{array}$ & $\begin{array}{c}\text { Stage A } \\
(n=11)\end{array}$ & $\begin{array}{l}\text { Stage B } \\
(n=14)\end{array}$ & $\begin{array}{c}\text { Stage C } \\
(n=14)\end{array}$ & $\mathrm{P}$ value ${ }^{\dagger}$ \\
\hline Tumor & & $\begin{array}{c}5 \\
(83.3 \%)\end{array}$ & $\begin{array}{c}5 \\
(45.5 \%)\end{array}$ & $\begin{array}{c}10 \\
(71.4 \%)\end{array}$ & $\begin{array}{c}7 \\
(50.0 \%)\end{array}$ & \multirow[t]{3}{*}{0.85} \\
\hline $\begin{array}{l}\text { Paired normal } \\
\text { mucosa }\end{array}$ & $\begin{array}{c}0 \\
(0 \%)\end{array}$ & $\begin{array}{c}1 \\
(16.7 \%)\end{array}$ & $\begin{array}{c}1 \\
(9 \%)\end{array}$ & $\begin{array}{c}1 \\
(7 \%)\end{array}$ & $\begin{array}{c}1 \\
(7 \%)\end{array}$ & \\
\hline $\mathrm{P}$ value* & & 0.01 & 0.029 & 0.0001 & 0.010 & \\
\hline
\end{tabular}

*Calculated by Student's t-test; the expression of LMW cyclin E between tumor and paired normal mucosa, ${ }^{\dagger}$ Calculated by Fischer's exact method; the expression of LMW cyclin E between tumor stages

tein expression pattern as the normal colon mucosa from the 12 healthy people (Fig. 1B, upper panel). The CDK2, a catalytic subunit for cyclin $\mathrm{E}$, was not overexpressed in the normal colon mucosa from the healthy people (Fig, 1A, lower panel), but the CDK2 protein expression was slightly increased in the adenomas compared to the surrounding normal tissues, but this was not significant (Fig. 1B, lower panel).

\section{2) LMW cyclin $\mathbf{E}$ expression in colorectal cancer}

Thirty nine colorectal cancer tissues, with paired surrounding normal mucosa, were used from the Dankook University Hospital Tissue Bank. The surrounding normal mucosa was taken from the site most proximal from the tumor. The cancer tissues were classified according to the modified Astler-Coller staging system 11 stage A, 14 stage B and 14 stage C colorectal cancers. Expression of the LMW cyclin E protein was noticed in 5 of the 11 in stage A (45\%), 10 of the 14 stage B (71\%) and 7 of the 14 stage $\mathrm{C}$ cancers $(50 \%)$. Conversely, the LMW cyclin E was expressed moderately in only 4 of the 39 (10\%) paired surrounding normal mucosa tissues. When compared with the surrounding normal mucosa, the expression of LMW cyclin $\mathrm{E}$ in the colon adenomas, and the various stages of cancer, were statistically significant $(p=0.01$ for adenoma, $\mathrm{p}=0.029$ for stage $\mathrm{A}, \mathrm{p}=0.0001$ for stage $\mathrm{B}, \mathrm{p}=0.01$ for stage $\mathrm{C}$ colorectal cancers, Table 1). Wild type cyclin $\mathrm{E}$ was also overexpressed compared with the surrounding normal tissues in most of the colon tumors, including the adenomas. The LMW cyclin E was expressed from an early stage in colorectal carcinogenesis, but this had no correlation with tumor progression ( $p=0.85$, Table 1). However, the smaller sized LMW cyclin $\mathrm{E}$ species were expressed more abundantly with tumor progression (Fig 2A, 2B and 2C, upper panel).

The overexpression of CDK2 was noticed in 19 of the 39 cancer tissues $(48.7 \%)$, one in stage A $(11 \%), 9$ in stage B (64\%) and 9 in stage $C$ cancers (64\%). The overexpression of CDK2 was not observed in the adenomas or the early stage of colorectal cancer (stage A, p=0.278, Table 2). The overexpression of CDK2 was only significant in an advanced stage of colorectal cancer (stages B and C, both $\mathrm{p}=0.004$, Table 2), and correlated well with the increased expression of the LMW cyclin $\mathrm{E}$ in all cases (Fig. 2A, 2B, 2C, lower panel each). The LMW cyclin $\mathrm{E}$ protein can also bind to $\mathrm{CDK} 2$, its catalytic

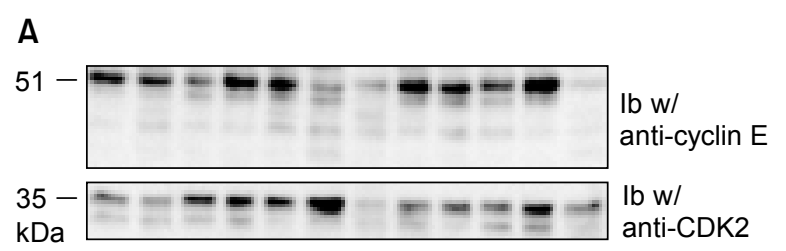

B

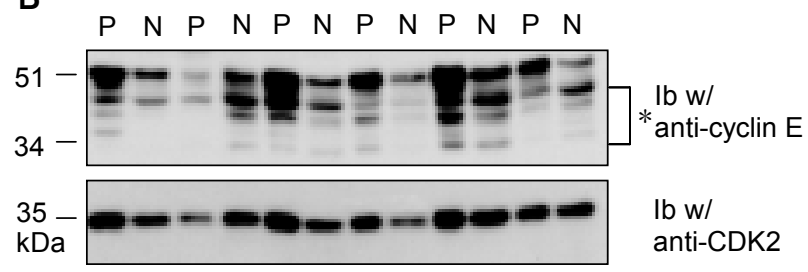

Fig. 1. Western blot analysis of cyclin $\mathrm{E}$ and CDK2 in normal colon mucosa, polyp and the surrounding normal mucosa. Western blot analyses were performed with cyclin E specific polyclonal (HE12, upper panel) and CDK2 specific antibodies (M2, lower panel) in normal colon mucosa, with no known disease (a), polyps with the surrounding normal mucosa (b). Thirty leg of total protein was loaded in each lane and the amount of protein normalized with Erk protein. There is no LMW cyclin E overexpression in the normal colon mucosa. The overexpression of LMW cyclin $\mathrm{E}$ protein was observed even in the small adenomas (less than $1 \mathrm{~cm}$ in size), but not in the paired normal mucosa. *: LMW cyclin $\mathrm{E}$ species. P: polyp, N: surrounding normal mucosa

subunit, similarly to the wild type cyclin E (Fig. 3).

\section{DISCUSSION}

Cyclin E gene amplification is an important event in some human cancers. Three changes in the expression of cyclin E, only in the cancerous tissues, were suggested: firstly, a 64 fold increased the cyclin $\mathrm{E}$ gene amplification and expression of cyclin E mRNA was noticed in some of the breast cancer tissues (21); secondly, loss of cyclin E expression control, 
Table 2. Overexpression of CDK2 in normal colon mucosa and various stages of colorectal cancer with paired surrounding normal mucosa

\begin{tabular}{|c|c|c|c|c|c|c|}
\hline & $\begin{array}{c}\text { Normal } \\
\text { colon mucosa } \\
(n=12)\end{array}$ & $\begin{array}{l}\text { Adenoma } \\
\quad(n=6)\end{array}$ & $\begin{array}{c}\text { Stage A } \\
(n=11)\end{array}$ & $\begin{array}{c}\text { Stage B } \\
(n=14)\end{array}$ & $\begin{array}{c}\text { Stage C } \\
(n=14)\end{array}$ & $\mathrm{P}$ value ${ }^{\dagger}$ \\
\hline Tumor & & $\begin{array}{c}0 \\
(0 \%)\end{array}$ & $\begin{array}{c}2 \\
(18.2 \%)\end{array}$ & $\begin{array}{c}9 \\
(64.3 \%)\end{array}$ & $\begin{array}{c}9 \\
(64.3 \%)\end{array}$ & 0.17 \\
\hline $\begin{array}{l}\text { Paired normal } \\
\text { mucosa }\end{array}$ & $\begin{array}{c}0 \\
(0 \%)\end{array}$ & $\begin{array}{c}0 \\
(0 \%)\end{array}$ & $\begin{array}{c}1 \\
(9 \%)\end{array}$ & $\begin{array}{c}1 \\
(7 \%)\end{array}$ & $\begin{array}{c}1 \\
(7 \%)\end{array}$ & \\
\hline $\mathrm{P}$ value* & & & 0.278 & 0.004 & 0.004 & \\
\hline
\end{tabular}

*Calculated by Student's t-test; the expression of Cdk2 between tumor and paired normal mucosa, ${ }^{\dagger}$ Calculated by Fischer's exact method; the overexpression of Cdk2 between tumor stages.

A

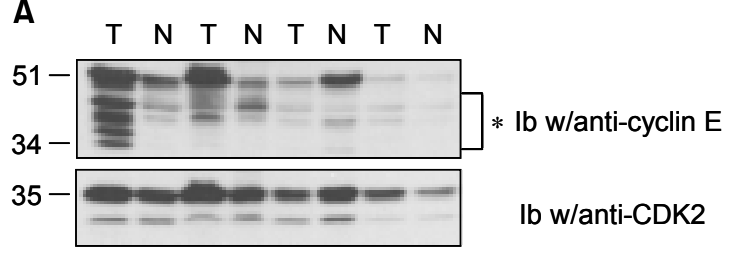

B

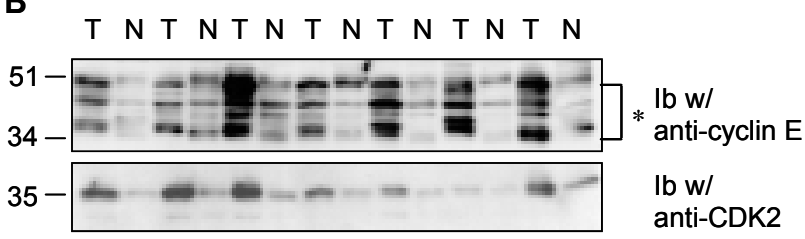

C

$T N T N T N T N T N T N T N$

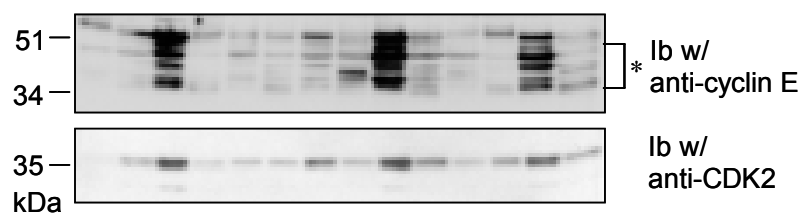

Fig. 2. Western blot analyses of cyclin $\mathrm{E}$ and CDK2 in colon cancers at various stages and of a pair of surrounding normal mucosa. Western blot analyses were performed with cyclin E specific polyclonal (HE12, upper panel) and CDK2 specific antibodies (M2, lower panel) at various stages in colorectal cancer tissue and paired normal mucosa. Thirty $\mathrm{Ig}$ of total protein was loaded in each lane and the amount of protein normalized with Erk protein. The overexpression of LMW cyclin E protein was observed in tumor tissues in stage A colon cancer (A), Stage B colon cancer (B), Stage C colon cancer (C), but not in the paired normal mucosa. *: LMW cyclin E species, T: tumor tissue, $\mathrm{N}$ : surrounding normal mucosa

according to the cell cycle, caused constitutively increased cyclin $\mathrm{E}$ associated kinase activity throughout the cell cycle in some cancers (22); thirdly, in cancer tissues, an increased

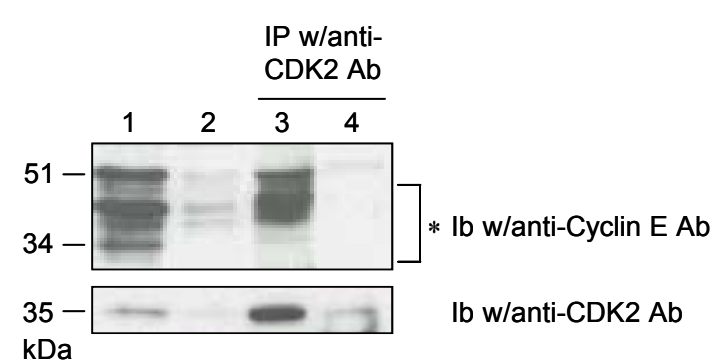

Fig. 3. Binding of LMW cyclin E to CDK2. The cancer tissue homogenate and cell lysate were immunoprecipitated with the CDK2 specific antibody. Lane 1; colon cancer tissue, Lane 2; paired normal mucosa to that in lane 1; Lanes 3 and 4 (same sample as in lanes 1 and 2); immunoprecipitated with the anti-CDK2 antibody (M2) and immunoblotted with the anti-cyclin E (BE12) (a, upper panel) and anti-cdk2 antibodies (A, lower panel). *: LMW cyclin E species

expression of wild type cyclin $\mathrm{E}$ was observed, but so was the LMW cyclin E expression, which was not detected in the normal cells and tissues (23). Even trophoblasts, which possess an ability of invasion similarly to cancer cells, can show seven different molecular weight cyclin E, ranging between molecular weights of 36 to $50 \mathrm{kDa}$, as in ovarian cancer (24).

LMW cyclin $\mathrm{E}$ was detected as molecular weight bands between $49 \sim 34 \mathrm{kDa}$, and in cancer cells, the LMW cyclin E, as well as the wild type cyclin E, were increased. There are two possible mechanisms for the generation of the LMW cyclin $\mathrm{E}$ in cancers - alternative splicing and posttranslational modification. If alternative splicing is the cause of the generation of the LMW cyclin E, there must be some other mechanisms that activates this alternative splicing in cancer tissues only. These alterations may affect the substrate specificity, intracellular localization and the stability of the cyclin E from proteolysis. Cyclin $\mathrm{E}$ is the only cyclin gene, where alternative splicing leading to structurally different proteins, has been described (15). However, these variants were detected in small amounts in both the tumor and normal tissues. It is not clear that all of the splice variants can produce the protein. About $50 \%$ of 
all cyclin E mRNA is translated to the wild type cyclin E, with a molecular weight of $51 \mathrm{kDa}$. Other mRNA cannot be translated to protein in normal cells, but in cancers it can be translated to active proteins (15), but the mechanism is unknown. However, it was recently reported that the LMW species were generated by posttranslational modification from its $51 \mathrm{kDa}$ species, and not by alternative splicing (16).

Cyclin E gene amplification is an important event in some human cancers, but is rarely found in colorectal cancers; in only $1(2.1 \%)$ of 47 cell lines and $5(9.4 \%)$ of 53 primary colorectal cancer tissues samples (25). In another report, there was no difference in the expression of the cyclin E protein between the tumor and surrounding normal mucosa tissues. Only the CDK2 protein level was increased in the colon cancer tissues, with the CDK2 kinase activity also increased in these tissues. Therefore, they suggest that the increased CDK2 kinase activity was caused by an increase in the CDK2 protein, and not by the cyclin E protein expression. However, conversely to this study, LMW cyclin E species have reportedly been observed in colon cancers. Although, the role of LMW cyclin E in colorectal cancers remains to be studied. It has also been reported that the overexpressions of cyclin E and LMW cyclin E were related to genetic instability $(17,18)$. It seems that genomic instability of the colon epithelium by LMW cyclin E expression may lead to epithelial proliferation. Therefore, it is our hypothesis that dysregulation of the cyclin $\mathrm{E}$ expression maybe an early contributing factor in colorectal carcinogenesis.

In this study, the expression of LMW cyclin E was shown to be elevated in colorectal cancer tissues, and is related with the early stage of colon carcinogenesis. The expression of LMW cyclin E protein was not detected in the normal mucosa from the healthy people, or in the normal mucosa from the adenoma and cancer patients. In the normal tissues, besides the major $51 \mathrm{kDa}$ cyclin E, two alternative spliced minor forms, a 45 and a $43 \mathrm{kDa}$ bands, were detected. The expression of the wild type cyclin $\mathrm{E}$ was also increased in the adenomas compared with the paired normal tissues, but the LMW cyclin $\mathrm{E}$ protein was only expressed in the adenomas. At various stages of colon cancers, the LMW cyclin E protein was only expressed in the cancer tissues, and not in the paired normal mucosa. The expression of the LMW cyclin E is significant in adenomas throughout the tumor progression compared to the surrounding normal colon mucosa. However, there was no correlation between the expression of LMW cyclin E and tumor progression. In an advanced stage, smaller sized cyclin $\mathrm{E}$ species were noted to be more abundant. Other factors initiating the hyperproliferation of colon epithelial cells can activate the mechanism that generates LMW cyclin E. In turn, the LMW cyclin E can modulate the cell cycle control mechanism to form an adenoma. LMW cyclin E may also be the initiating factor of colon carcinogenesis, and to prove this, a study on the expression of LMW cyclin E in aberrant crypt foci, which is a very early stage of colon carcinogenesis, will be conducted. The expression of the CDK2 protein was not increased in the normal colon mucosa of the healthy persons or the colon adenomas compared to that in the surrounding normal mucosa. Even in stage A colon cancers; there was no increased CDK2 protein expression compared to the surrounding normal mucosa. Only in advanced stage colorectal cancer tissues was the overexpression of the CDK2 protein statistically significant compared to the surrounding normal mucosa. CDK2 protein was overexpressed in the cases where the LMW cyclin E protein was expressed. From these results, the overexpression of the CDK2 protein, and its increased kinase activity, has an important role in the progression of colorectal cancer, but not in its initiation. The overexpression of the CDK2 protein may not be a causative factor in the initiation of the carcinogenesis of colorectal epithelial cells. It is not clear, but there is a possibility that the overexpression of the CDK2 protein is a consequence of a deregulated cell cycle mechanism in colorectal cancer. The LMW cyclin E species can also bind to CDK2, its catalytic partner. Therefore, it is suggested that the LMW cyclin E can bind to make an active kinase complex. Porter reported that the LMW cyclin E/CDK2 had a more active kinase activity for $\mathrm{pRB}$ as the substrate, and was constitutively active regardless of the cell cycle stage (16). LMW cyclin E may also have kinase activity toward other unknown substrates that are not phosphorylated by cyclin E/CDK2 under normal conditions. A constitutively active kinase complex, LMW cyclin E/CDK2, may be responsible for the hyperproliferation state of colon cells in the early stage of colon carcinogenesis.

\section{CONCLUSIONS}

It is suggested that the dysregulation of the cyclin E, which generate the LMW cyclin E, has an important role in the early stage of colon carcinogenesis.

\section{REFERENCES}

1. Sherr CJ. Cancer cell cycles. Science 1996;274:1672-1677.

2. Ohtsubo M, Roberts JM. Cyclin-dependent regulation of G1 in mammalian fibroblasts. Science 1993;259:1908-1912.

3. Won KA, Reed SI. Activation of cyclin E/CDK2 is coupled to site-specific autophosphorylation and ubiquitin-dependent degradation of cyclin E. EMBO J 1996;15:4182-4193.

4. Dou Q-P, Levin AH, Zhao S, Pardee AB. Cyclin E and cyclin $A$ as candidate for the restriction point protein. Cancer Res 1993;53:1493-1497.

5. Dyson N. The regulation of E2Fby pRB-family proteins. Genes Dev 1998;12:2245-2262.

6. Ohtani K, DeGregori J, Nevins JR. Regulation of the cyclin E gene by transcription factor E2F1. Proc Natl Acad Sci USA 1995;92:12146-12150.

7. Geng Y, Whoriskey W, Park MY, Bronson RT, Medema RH, Li T, Weinberg RA, Sicinski P. Rescue of cyclin D1 deficiency by knockin cyclin E. Cell 1999;97:767-777.

8. Harwell RM, Porter DC, Danes C, Keyomarsi K. Processing of cyclin $\mathrm{E}$ differs between normal and tumor breast cells. Cancer Res 2000;60:481-489.

9. Richardson H, O'Keefe LV, Marty T, Saint R. Ectopic cyclin $\mathrm{E}$ expression induces premature entry into $\mathrm{S}$ phase and disrupts pattern formation in the Drosophila eye imaginal disc. Development 1995;121:3371-3379.

10. Smith E, Frenkel B, MacLachlan TK, Giordano A, Stein JL, Lian JB, Stein GS. Post-proliferative cyclin E-associated kinase activity in differentiated osteoblasts: inhibition by proliferating osteoblasts and osteosarcoma cells. J Cell Biochem 


$$
\text { 1997;60:141-152. }
$$

11. Keyomarsi K, O'Leary N, Molnar G, Lees E, Fingert HJ, Pardee AB. Cyclin E, a potential prognostic marker for breast cancer. Cancer Res 1994;54:380-385.

12. Han SH, Park KM, Bae BN, Ryu SY, Kim KH, Kim HJ, Kim YD, Kim HY. Interrelation of cyclin D1, cyclin E, and p27kip1 expression on tissue array of breast cancer. Cancer Res Treat 2002;34:388-393.

13. Yasui W, Kunuyasu H, Yokozaki H, Semba S, Shimamoto F, Tahara E. Expression of cyclin E in colorectal adenomas and carcinomas: correlation with expression of $\mathrm{Ki}-67$ antigen and p53 protein. Virchows Arch 1996;429:13-19.

14. Furihata M, Ohtsuki Y, Sonobe H, Shuin T, Yamamoto A, Terao N, Kuwahara M. Prognostic significance of cyclin E and p53 protein overexpression in carcinoma of the renal pelvis and ureter. Br J Cancer 1998;77:783-788.

15. Porter DC, Keyomarsi K. Novel splice variants of cyclin E with altered substrate specificity. Nucleic Acids Res 2000; 28:E101

16. Porter DC, Zhang N, Danes C, McGahren MJ, Harwell RM, Faruki S, Keyomarsi K. Tumor-specific proteolytic processing of cyclin E generates hyperactive lower-molecular weight forms. Mol Cell Biol 2001;21:6254-6269.

17. Simone C, Resta N, Bagella L, Giordano A, Guanti G. Cyclin $\mathrm{E}$ and chromosomal instability in colorectal cancer cell lines.
J Clin Pathol Mol Pathol 2002;55:200-203.

18. Sutter T, Dansranjavin T, Lubinski J, Debniak T, Giannakudis J, Hoang-Vu C, Dralle H. Overexpression of cyclin E protein is closely related to the mutator phenotype of colorectal carcinoma. Int J Colorectal Dis 2002;17:374-380.

19. Sutter T, Doi S, Carnevale KA, Arber N, Weinstein IB. Expression of cyclin D1 and $\mathrm{E}$ in human colon adenocarcinomas. J Med 1997;28:285-309.

20. Laemmli UK. Cleavage of structural proteins during the assembly of the head of bacteriophage T4. Nature 1970;227:680-685

21. Buckley MF, Sweeney KJE, Hamilton JA, Sini RL, Manning DL, Nicholson RI, deFrazio A, Watts CKW, Musgrove EA, Sutherland RL. Expression and amplification of cyclin genes in human breast cancer. Oncogene 1993;8:2127-2133.

22. Gray-Bablin J, Zalvide J, Fox MP, Knickerbocker CJ, DeCaprio JA, Keyomarsi K. Cyclin E, a redundant cyclin in breast cancer. Proc Natl Acad Sci USA 1996;93:15215-15220.

23. Keyomarsi K, Conte Jr D, Toyofuku W, Fox MP. Deregulation of cyclin E in breast cancer. Oncogene 1999;11:941-950.

24. Bukovsky A, Cekanova M, Caudle MR, Wimalasena J, Foster JS, Keenan JA, Elder RF. Variability of placental expression of cyclin E low molecular weight variants. Biol Reprod 2002; 67:568-574.

25. Leach FS, Elledge SJ, Sherr CJ, Willson JK, Markowitz S, Kinzler KW, Vogelstein B. Amplification of cyclin genes in colorectal carcinomas. Cancer Res 1993;53:1986-1989. 